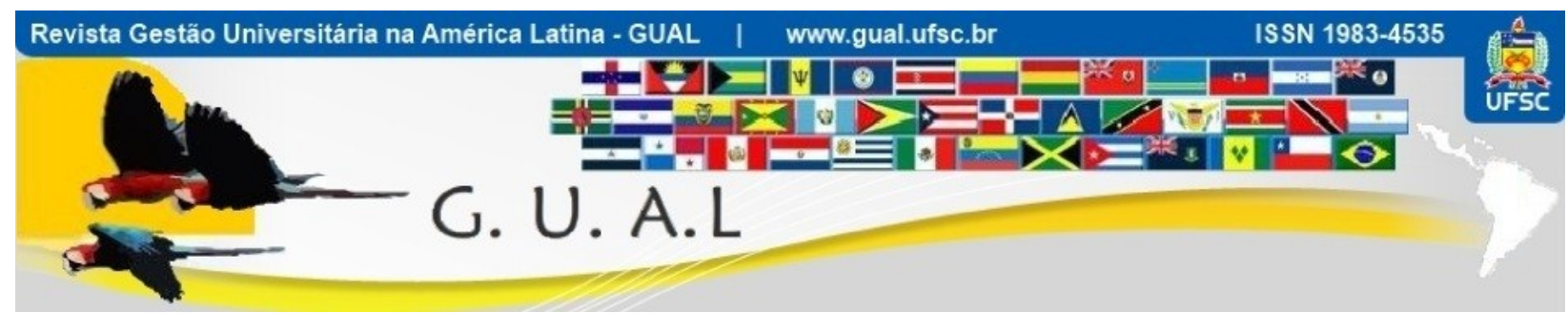

DOI: http://dx.doi.org/10.5007/1983-4535.2013v6n2p22

\title{
ENSINO SUPERIOR À ORDEM DO CAPITAL INTERNACIONAL
}

\section{HIGHER EDUCATION AT THE SERVICE OF THE INTERNATIONAL CAPITAL}

Vanessa Maria de Oliveira Borges, Mestre Centro Universitário Jorge Amado - UNIJORGE vanessaborges23@gmail.com

Edson Tomaz de Aquino, Doutor Centro Universitário Jorge Amado - UNIJORGE etomaz18@yahoo.com.br

Recebido em 06/fevereiro/2013

Aprovado em 26/março/2013

Sistema de Avaliação: Double Blind Review

Esta obra está sob uma Licença Creative Commons Atribuição-Uso. 


\title{
RESUMO
}

A formatação e o reordenamento de poder do mundo atual não excluem a organização universitária. O entorno político, econômico, social e cultural exercem um enorme impacto na educação superior, que não pode e nem deve ficar de fora das mudanças que se apresentam na sociedade. É por isso que a cooperação internacional vem se implantando como um processo de grande relevância no mundo universitário, sendo ponto de discussão acadêmica em diversos países. Por outro lado, a redução da interferência do Estado na economia e a internacionalização dos serviços, permite que o ensino superior seja tratado como uma commodity no comércio internacional. Nesse contexto, o presente estudo visa analisar os elementos políticos centrais do debate sobre a incorporação, cada vez maior, das demandas do capital internacional na educacional brasileira. Para viabilizar o alcance dos objetivos dessa pesquisa - dentre os quais, analisar a ação ofensiva do capital internacional no ensino superior brasileiro - será utilizado como referencial teórico, o Paradigma Globalista das Relações Internacionais, sob a perspectiva da Teoria da Dependência e as relações centro-periferia. Os procedimentos metodológicos utilizados para a realização deste artigo permitem qualificá-lo como resumo de assunto (quanto à sua natureza) e como explicativa (quanto aos seus objetivos). Os procedimentos de coleta de dados voltaram-se para a obtenção de dados secundários, já publicados em livros, artigos, periódicos, sites etc. Deste modo, este trabalho qualifica-se como bibliográfico, no que se refere ao seu objeto, e qualitativo no que diz respeito à sua abordagem, realizando, assim, uma análise interpretativa dos dados obtidos e dos fenômenos observados.

Palavras-chave: Ensino Superior. Desenvolvimento. Capital Internacional. Internacionalização.

\begin{abstract}
The arranging and the reordering of power in today's world do not exclude the university organization. The political, economic, social and cultural surroundings exerts a huge impact on higher education, which can not and should not stay out of the changes that arise in today's society. That is why international cooperation has been deployed as a process of great relevance in the university world, being the point of academic discussion in several countries. Moreover, the reduction of the states interference in their economies plus the internationalization of services, make the higher education be treated as a commodity in the international market. In this context, this study aims to examine the elements of the central political debate about the demands of the international capital in Brazilian higher education. To facilitate the achievement of the goals of this research - among them, analyze the offensive action of international capital in Brazilian higher education - will be used as theoretical framework, the Globalist Paradigm of International Relations, from the perspective of the Dependency Theory and the center-periphery relations. The method of research used is qualified as explanatory (as to their goals) and as abstract subject (in nature). The procedures for data collection turned to obtaining secondary data, already published in books, articles, journals, websites etc. Thus, this work qualifies itself as bibliographic, with regard to its object, and qualitative with regard to its approach, realizing thus an interpretive analysis of the data obtained and the observed phenomena.
\end{abstract}

Keywords: Higher Education. Development. Capital International. Internationalization. 


\section{INTRODUÇÃO}

No cenário internacional que se formata, com a era da informação e da globalização, a Cooperação Internacional Universitária (CIU), é um quesito inevitável que toda Instituição de Ensino Superior (IES) deve considerar, como imperativo de sobrevivência no competitivo mercado global. Presenciamos uma nova configuração no modo de fazer negócios e nos estilos de vida, cada vez mais caracterizada pela mobilidade e pela conectividade. Nesse contexto, as IES devem buscar ampliar as suas competências como agentes produtores de novos conhecimentos, investindo no intercambio de pesquisadores, estudantes e professores com capacidade de contribuir, através de suas multiplicidades de visões de mundo, para ampliar o nível de pesquisa e de ensino das IES e, preparar os estudantes locais para que, ao retornarem, estejam aptos a atender às necessidades e demandas regionais. Stallivieri (2004) retrata as ações da CIU, como uma tendência que "não pode mais ser encarada como um luxo, mas sim como resposta ao fenômeno da globalização". O que antes era apenas uma opção de algumas IES, torna-se imperativo na medida em que os mercados de trabalho superam as fronteiras territoriais e as universidades têm entendido essa nova demanda por profissionais que dominem idiomas e saibam atuar em mercados multiculturais.

A crescente valorização do capital intelectual dos indivíduos, a revolução da informação e dos meios de comunicação e a responsabilidade na criação e manutenção do entendimento entre os povos e do espírito de solidariedade com os países menos desenvolvidos, passam a ser questões permanentes discutidas em fóruns internacionais e vem sendo claramente apresentadas nas conferencias mundiais sobre ensino superior da UNESCO. Essas questões desafiam a universidade a atualizar suas estratégias, de modo que seus acadêmicos passem a contar com as aptidões essenciais que lhes permitam interagir numa sociedade cada vez mais internacional, com rápidas mudanças em seus sistemas.O processo de globalização passa a ser pensado, então, como um paradigma que requer novos padrões. Um dos padrões sempre apontados é o da competitividade, e entre seus preceitos está o domínio da tecnologia e do conhecimento. consequentemente, a educação passa a ser considerada fundamental para uma inserção mais vantajosa no mercado globalizado.

Nesse contexto, a globalização não será entendida apenas como o termo que designa a crescente interdependência e interligação entre os Estados, promovida, sobretudo através da liberalização do comércio mundial, da desregulamentação financeira e dos avanços tecnológicos nas telecomunicações, tecnologias de informação e transportes. A globalização, 
neste trabalho, será entendida como parte de um processo histórico de predomínio econômico e de expansão do capitalismo, cujas alterações provocadas na conjuntura internacional contemporânea, alavancaram o consumo e abriram novos mercados, diminuído as distancias físicas entre os povos e ressaltando suas diferenças culturais.

Entendo, portanto, que o processo de globalização neoliberal reflete localmente e as IES não estão à parte deste. As discussões sobre esse modelo apresentam análises distintas, algumas tradicionais e conservadoras - enfatizando os benefícios oriundos de suas dinâmicas -, outras mais críticas, dando destaque à competitividade e ao modelo agressivo que a busca por mercados que simboliza. Milton Santos trata desse dualismo ao refletir sobre o que chama de "globalização enquanto fábula" e "globalização perversa". Em verdade, a promoção do modelo neoliberal, que torna o Estado-Nação parte de uma lógica de reprodução do capital internacional, enfraquecendo-o sob a égide da interpretação de que o mercado é o principal agente promotor do desenvolvimento, é uma das resultantes desse processo. Ao Estado, caberia apenas o papel de garantir as condições para o desenvolvimento livre das dinâmicas econômicas neoliberais.

Coadunante com esta perspectiva e, em consequência da variedade de abordagens e conceitos utilizados para se entender as ações internacionais no âmbito do ensino superior, se faz necessária uma definição do termo "Internacionalização" neste trabalho. Embora, na literatura especializada, este termo também possa se referir aos processos de cooperação entre IES de diferentes países, neste trabalho ele estará relacionado às atividades com motivação econômica, se referindo assim ao comércio internacional de serviços educacionais.

\section{O CONTEXTO DA INTERNACIONALIZAÇÃO}

Diante do novo cenário internacional que se coloca para todas as nações, reafirma-se a necessidade de se estudar e compreender melhor como os países atuam frente aos novos desafios de tal conjuntura. Num mundo de crescente multipolaridade, o entendimento do "outro" e a busca por mecanismos cooperativos que propiciem uma inserção mais sólida, pautada na defesa dos interesses nacionais, se tornam indispensáveis. A universidade exerce aí um papel fundamental como espaço gerador de conhecimento e, sua atuação enquanto sujeito ativo de cooperação internacional, no sentido de proporcionar aos seus alunos a oportunidade de vivenciar experiências fora de seu país, faz parte do papel daquelas que procuram um equilíbrio entre as demandas regionais e os desafios mundiais. 
No entanto, na leitura de textos referentes ao processo de atuação internacional das IES, percebe-se a predominância de uma espécie de pensamento único, dominante, acrítico. A literatura, em sua maioria, versa apenas sobre as características do processo de atuação internacional das IES, como se o mesmo fosse dado, natural, não se debruçando sobre sua gênese, ideologia e interesses políticos. Há uma grande quantidade de textos demasiado descritivos, e até com caráter de manuais especificamente no que se refere à temática cooperação internacional e da realização de ações conjuntas realizada entre as IES. Não se trata de tirar ou diminuir a importância dessas ações pois esta autora acredita e defende a inserção de tópicos de experiências internacionais nos currículos mas, como parte real do processo de globalização, o ensino superior já não pode ser visto em um contexto estritamente nacional. Considerada parte integrante da política de um país, a cooperação internacional não é um espaço pautado exclusivamente por motivações filantrópicas, mas reflete, acima de tudo, os interesses nacionais das partes envolvidas e, a forma como esses interesses são ajustados é que determina o caráter mais solidário ou hegemônico dessas iniciativas

Coadunante com este ponto de vista, faz-se necessário estudar as relações de dependência e interdependência presentes nas relações internacionais. Nesse cenário de desigualdades e de interesses distintos, onde o Estado-Nação perdeu a capacidade, por si só, de conduzir e assegurar a estabilidade das relações entre os Estados e com os novos atores, somado à concepção atual de que a educação é um pré-requisito essencial para o desenvolvimento econômico, as IES dos países em desenvolvimento/subdesenvolvidos acabam se tornando mercados na reprodução do capital, explorados pelas grandes empresas da economia central do capitalismo.

A partir do paradigma Globalista das Relações Internacionais, essa análise pode ser feita a partir da ideia de que a evolução do sistema capitalista decorre de mecanismos de dominação, que favorecem o próprio sistema em prejuízo dos outros. Os globalistas ressaltam a manutenção e o alargamento das relações de dependência entre desenvolvidos e em desenvolvimento/subdesenvolvidos, observando que a estrutura político-econômica internacional foi construída intentando manter o status quo. "Os globalistas crêem que a economia é a chave para se entender a criação, evolução e funcionamento do sistema internacional" (VIOTTI, 1998, pgs. 9 e 10). Esse seria, portanto, um aparato integrado capitalista em busca de acumulação de capital. 
Dentro do paradigma Globalista, bebendo na fonte das ciências econômicas e recebendo um aporte teórico das correntes marxistas, surge o paradigma da dependência que, a partir da ascendência de novos atores, novas pautas na agenda internacional e da necessidade de explicar a nova configuração de poder que se formava, percebia as relações de domínio e submissão, força e poder se reproduzindo no sistema internacional. Uma vez que os fluxos ocorrem numa intensidade muito grande, com diversos atores interagindo em níveis variados, forma-se uma teia de relações interdependentes e, nesse cenário assimétrico, com desigualdades sociais, econômicas e políticas, é possível perceber que ao mesmo tempo em que as relações de interdependência entre os atores aumentavam as possibilidades de intercambio e de fluxos internacionais, produzem também condições para arraigar essas relações assimétricas entre eles, podendo criar relações de pura dependência. Essa dependência não estaria limitada apenas ao campo comercial, como concordam Duarte e Graciolli (2012):

Do ponto de vista estritamente econômico, essa teoria entendia que as relações estruturais de dependência estavam para além do campo das relações mercantis - como acreditavam os teóricos desenvolvimentistas - se configurando também no movimento internacional de capitais, em especial na figura dos investimentos direto estrangeiros e na dependência tecnológica. A esses fatores, somava-se o imperialismo, que na medida em que permeava toda a economia e sociedade dependentes, representava um fator constitutivo de suas estruturas sócio-econômicas. Era a conjunção desses distintos mecanismos que integravam, de forma subordinada, a economia latino-americana à economia internacional.

Não é por se tratar de relações de interdependência, que pode-se pensar que essas relações são pautadas pela igualdade. A teoria da interdependência tem como visão central a ideia de que a arena internacional apresenta desequilíbrios, que produzem situações de injustiça em que a condição de subdesenvolvimento de alguns Estados é conseqüência da riqueza de outros. Essa relação de subordinação e dependência, subdesenvolvimento e desenvolvimento, não se colocam como etapas de um mesmo processo evolutivo, mas como realidades conectadas em sua estrutura, mas contrapostas e distintas . Dessa forma, "o subdesenvolvimento passa a ser visto como um produto do desenvolvimento capitalista mundial sendo, por isso, uma forma específica de capitalismo" (DUARTE e GRACIOLLI, 2012). 


\section{A DESNACIONALIZAÇÃO DO ENSINO SUPERIOR BRASILEIRO}

O ensino superior do Brasil vivenciou um período de relativa estagnação, quando crescia apenas cerca de 1,3\% ao ano, até meados da década de 1990. A partir dos anos 2000, apresentou uma crescente de $17 \%$, assinalada principalmente pela ampliação do setor privado da educação superior. A partir desse cenário, pôde ser observado o crescente interesse de investidores internacionais na compra dessas IES, fenômeno que se convencionou chamar de desnacionalização do ensino superior brasileiro. Para muitos - e esta opinião é compartilhada por esta autora - esse processo representa apenas uma transação para o capital especulativo internacional, interessado somente em expandir seus lucros. Segundo Santos (2000, p. 81), "com a globalização todo e qualquer pedaço da superfície da Terra se torna funcional às necessidades, usos e apetites de Estados e empresas nesta fase da história”. O Brasil, por conta da abertura do mercado para a iniciativa privada, de sua estabilidade econômica e do boom de IES particulares iniciado na segunda metade dos anos 90, pode ser percebido como um mercado com grande potencial a ser explorado, configurando um cenário atrativo aos “investidores" estrangeiros.

Atualmente, no Congresso Nacional Brasileiro, tramita um projeto de lei que prevê uma reforma universitária, na qual grupos internacionais terão direito de aquisição de até 30\% das ações de uma IES. Enquanto esse projeto não é votado, o capital estrangeiro reforça o caráter mercantil deste que é um setor estratégico para o desenvolvimento do país. A exploração do ensino superior privado brasileiro por grupos estrangeiros, cria uma dependência da produção de ciência, pesquisa e ensino no nosso país, evidenciando uma propensão preocupante para a educação nacional: termos nas nossas IES particulares, características de ensino e diretrizes de pesquisa estabelecidas e controladas por interesses terceiros, fora do nosso centro de decisão.

Os países desenvolvidos, que já contam com grande percentual de sua população escolarizada e uma taxa de natalidade decrescente, não se apresentam mais como um mercado atrativo para as empresas que atuam no setor educacional. Por outro lado, os países em desenvolvimento - que contam com grande parte da sua população em idade escolar, consequentemente se mostrando um mercado potencial para oferta de ensino nos vários níveis - tem sido, cada vez mais, alvo do capital internacional.

[...] os pressupostos neoliberais partiam da premissa de que se os países que realizassem uma liberalização financeira de seus respectivos mercados, aumentando o grau de exposição às finanças internacionais (liberalização 
financeira), por meio da abertura da conta de capital, alcançariam melhores condições de financiamento para modernização da capacidade produtiva. Segundo esses pressupostos, como os países da periferia apresentam uma relativa escassez de capital, por isso apresentando condições de financiamento menos favoráveis, a liberalização permitiria ampliar o mercado de capitais e créditos, elevando a concorrência. Com isso, os agentes econômicos teriam possibilidades mais abrangentes de alocar capital [...] (GOMES, 2009, p. 207-208).

A idéia por trás da regulamentação da educação via Organização Mundial do Comércio (OMC), é a criação de um mercado aberto e global, onde a educação, vista como um serviço, possa ser negociada pelo melhor preço. O Brasil não assumiu nenhum compromisso ou apresentou ofertas no que diz respeito à liberalização de serviços educacionais. Ainda assim, o mercado de serviços no ensino superior no país é relativamente aberto. Existem poucas restrições à participação de capital estrangeiro nas entidades privadas de ensino superior e grupos internacionais têm adquirido participação acionária em muitas IES brasileiras. Segundo dados da Universia (2010), a educação superior já é a terceira área com maior número de fusões e aquisições no Brasil, sendo que mais de 50\% das ações das IES disponíveis na Bolsa de Valores foram compradas por investidores estrangeiros.

No centro desse debate, está um confronto de valores básicos. Se por um lado, há aqueles que vêem a educação apenas como um empreendimento comercial, pelo outro lado, há aqueles que afirmam que a educação é acima de tudo, um direito humano e um bem público, e que as forças do mercado não podem garantir a manutenção de um sistema de ensino acessível e de alta qualidade. Segundo Celli (2008):

Uma série de princípios-chave são essenciais para a integridade da educação, e sua capacidade de desempenhar o seu papel vital na sociedade como um gerador imparcial e disseminador do conhecimento. A primeira delas é o fato de que a educação é um direito humano. O segundo é o princípio do serviço público. A educação é um bem público que deve ser entregue por meio de instituições públicas - e com a ética do setor público - enfatizando acesso, qualidade e igualdade de oportunidades.

É certo que os países devem investir maciçamente em seus sistemas de ensino, pois assim elevam sua competitividade e melhoram a distribuição da renda. O problema é que a incoerência dos processos de internacionalização das IES privadas brasileiras são resultantes das desigualdades das relações centro-periferia, onde o intento não é formar profissionais que sejam capazes de se engajar no desenvolvimento nacional. Na lógica do lucro a qualidade da educação não é prioridade, o que importa é quantidade e retorno financeiro. 
O "espírito comercial", para a sua plena realização, exige a fragmentação, a mecanização e a reificação de todas as relações humanas. É por isso que a sorte do "ideal de universalidade", expresso nas grandes utopias educacionais do passado, foi selada na forma que todos sabemos. O que decidiu a forma dessas utopias no momento mesmo de sua concepção foi o fato de pretenderem produzir seus efeitos no lugar das modificações sociais necessárias, e não através delas. (MĖSZÁROS, 1981, pg. 269).

É certo que qualquer iniciativa envolvendo mudanças gera debate, especialmente se for uma questão sensível como a educação. Neste caso, no entanto, é possível identificar mais pontos fracos que fortes, mais ameaças que oportunidades. Entre as ameaças sentidas pelo setor, a maior delas talvez seja o medo do abandono da responsabilidade do Estado na área da educação superior, com o risco de que a educação seja entregue ao domínio estrangeiro, perpetuando uma relação assimétrica de poder já existente e trazendo implicações não só em termos qualitativos, mas culturais.

A educação deixou de ser apenas mais um direito fundamental consagrado na Declaração Universal dos Direitos Humanos, a que todo ser humano pode aspirar, legitimamente, para sua realização pessoal. Ela passou a ser a precondição essencial para qualquer tipo de desenvolvimento, para a redução da taxa de desemprego e da pobreza, para o progresso social e cultural, para a promoção de valores democráticos e para o estabelecimento de uma paz duradoura" (CARNOY, 2004).

A partir do pensamento de Carnoy, coloca-se o seguinte questionamento: Por que permitir que a educação, fator fundamental para o crescimento de qualquer nação, exerça um papel de coadjuvante frente aos interesses do mercado externo? É inegável o papel estratégico que a educação desempenha em qualquer projeto de desenvolvimento nacional mas, no processo, como ele se coloca hoje e como se vê projetado para o futuro, o que se observa é uma relação desigual de controle por parte dos países desenvolvidos e de uma perda de controle dos subdesenvolvidos sobre seus recursos. Temos, então, uma relação desigual em sua essência porque - mais uma vez - o desenvolvimento de alguns está ocorrendo às custas do subdesenvolvimento de outros.

\section{CONSIDERAÇÕES FINAIS}

A discussão até aqui desenvolvida permite o entendimento do tipo de internacionalização universitária proposto pela OMC. De acordo com a inserção da educação no GATTS, proposta pelos EUA e apoiada pelos países desenvolvidos, a educação é remetida à condição de mercadoria, com objetivos voltados apenas para a lucratividade. Como 
desdobramento, o mercado brasileiro estaria aberto (e vulnerável) para grupos "educacionais" estrangeiros, que formariam profissionais nas áreas de seu próprio interesse, com valores, habilidades e cultura desenvolvidos a partir de interesses externos.

“A educação é uma dimensão da vida, que se transforma historicamente, acompanhando e articulando-se às transformações dos modos de produzir a existência humana" (MÉSZÁROS, 2007). A organização e os modelos de desnacionalização dos sistemas educacionais estariam seguindo esse mesmo propósito, direcionando a educação à lógica do capital internacional, adquirindo funções direcionadas para perpetuação das relações dominantes. "A educação tem duas principais funções na sociedade: (1) A produção das qualificações necessárias ao funcionamento da economia e; (2) A formação de quadros e a elaboração dos métodos para um controle político.” (MÉSZÁROS, 2007, p. 273).

Assim, os processos de venda do ensino superior brasileiro ao capital internacional não visam a humanização, a socialização ou a "universalidade" do conhecimento, mas sim uma adaptação às novas formas sociais de produção e reprodução do sistema capitalista, partindo do pressuposto de que quem é hegemônico concebe a política econômica internacional de modo a poder sustentar seus próprios interesses e ideologias. As motivações que acompanham as estipulações dos grupos "educacionais" internacionais não objetivam a melhor formação do discente, nem a atualização de conteúdos, especialização de docentes ou incentivo à pesquisa.

Pensar a educação a partir de uma dinâmica estrita de mercado, compromete o futuro e o desenvolvimento dos Estados, conservando-os em seus papeis de periferia. A educação na agenda do GATS, como um serviço comercial, e a consequente entrada do capital internacional no mercado do ensino superior brasileiro, implica na diminuição de barreiras para o "livre comércio" do setor, num caminho que pode levar à perda da autonomia universitária e da diversidade cultural.

\section{REFERÊNCIAS}

CARNOY, Martin. A Educação na América Latina está preparando sua força de trabalho para as economias do século XXI? Ed. UNESCO, 2004.

CELLI, H. Serviços educacionais no GATS: desafios para o Brasil. Revista International Trade and Susteinable Development, v. 4, 2008.

DUARTE, Pedro Henrique; GRACIOLLI, Edílson. A Teoria Da Dependência: interpretações Sobre o (Sub)Desenvolvimento na América Latina. Disponível em: 
http://www.unicamp.br/cemarx/anais v coloquio arquivos/arquivos/comunicacoes/gt3/sessa o4/Pedro Duarte.pdf. Acesso em: Jun/2012.

GACEL-ÁVILA, J. Internacionalización de la Educación Superior en América Latina y el Caribe. Disponível em: www.geocities.ws/profejoako/jocelyn.doc Acesso em: 17 abr. 2011.

GOMES, Fábio Guedes. Estado capitalista, Plano Real e Acumulação financeira. In: GOMES, Fábio Guedes; PINTO, Eduardo Costa (orgs.). Desordem e Regresso: o período de ajustamento neoliberal no Brasil, 1990-2000. São Paulo: Mandacaru: Hucitec, 2009.

MARINI, Ruy Mauro. Dialética da dependência. In: SADER, Emir. Dialética da Dependência. Petrópolis: Vozes, 2000.

MÉSZÁROS, I. O desafio e o fardo do tempo histórico. São Paulo: Boitempo, 2007.

NYBORG, P. Institutional autonomy. Relations between state authorities and higher education institutions. Journal of Education Policy, v.20, n.3, p. 313 - 345, 2002.

SANTOS, Milton. Por uma outra globalização: do pensamento único à consciência universal. 3. ed. Rio de Janeiro: Record, 2000.

SANTOS, Theotônio. O debate sobre a dependência. In: Teoria da dependência: balanço e perspectivas. Rio de Janeiro: Civilização Brasileira, 2000.

STALLIVIERI, Luciane. Estratégias de internacionalização das universidades brasileiras. Caxias do Sul: Universidade de Caxias do Sul, 2004.

UNIVERSIA. [Portal]. Disponível em: www.universia.com.br Acesso em: 25 jun. 2010.

VIOTTI, Paul R. et. al. Theory, images, and international relations: an introduction. In:

International Relations Theory: Realism, Pluralism, Globalism, and Beyond. Boston: Allyn and Bacon, 1999. 